\title{
鋼の疲労の統計的性質および疲労強度と非金属介在物"
}

\author{
横 堀 武夫** 前川 一 郎*** 是川誠 一****
}

\section{The Influence of Non-metallic Inclusions on the Fatigue Strength and the Statistical Nature of Steel}

by

\author{
Takeo Yokobori, Ichiro MAEKAwa and Seiichi KoREKAWA \\ (Facutly of Engineering, Tohoku University)
}

Three series of specimens were specially prepared so that they may contain various degrees of $\mathrm{MnS}$ non-metallic inclusions, other parameters being kept constant especially the amount of manganese in solution as much as possible. Fatigue tests were carried out with a rotating bending fatigue machine.

The results obtained are as follows:

(1) The definite relationship could not be recognized between the inclusion ratings and the statistical nature of fatigue life of steel, which is in accordance with the previous work by one of the present authors, but contrary to the result by Epremian and Mehl.

(2) The ferrite grain size is a predominant metallurgical factor in the statistical nature of fatigue fructure of steel.

(3) For the same stress amplitude, the scatter of fatigue life increases and the probability of fructure decreases with the decrease of grain size.

(4) For the equivalent stress amplitude, the scatter of fatigue life appears not to be affected by inclusion ratings and ferrite grain size.

(5) The longitudinal fatigue strength of carbon steel is not so much affected by the content of $\mathrm{MnS}$ as inclusions. The effect by ferrite grain size or other statistical parameters may also be large.

(Received Nov. 8, 1962)

\section{1. 緒}

他の条件を同一に保って，同一材について介在物の 量だけを变えて疲労強度を系統的に調べた研究はいま だほとんど知見しない，著者の一人はさきに種々の炭 素鋼の疲労破壊の統計的性質と介在物およびフェライ 卜結晶粒度との関係を調べた。ここでは化学成分など 他の条件はできるだけ同一に保って(例えば固溶 $\mathrm{M}_{n}$ の量をほ涪等しく保うようにした)， $\mathrm{M}_{n}$ と $\mathrm{S}$ の量の配 合を変えることによって介在物としての $\mathrm{M}_{n} \mathrm{~S}$ の量を 徽量からきわめて多量の範囲に至るまで変えて $(\mathrm{S} の$ 含有量を $0.010 \sim 0.340 \%$ まで変えて)調製された炭素 鋼(S15C)について疲労の統計的性質拈よび疲労強度 を調へた結果を述べるこの調製の際フェライト結

\footnotetext{
* 原稿受付 昭和37年11月 8 日

** 正員 東北大学工学部 $* * *$ 東北大学工学部

***** 現在東北大学教育教養部
}

晶粒度も多少变ったのであるが，その影響も調べてあ る。なお， $\mathrm{M}_{n} \mathrm{~S}$ 介在物の疲学強度に及隹す影響の研 究としては，英国鉄鋼協会の介在物小委員会が中心と なった研究があるが，そこではS 含有量を $0.04 \%$ ま で增すことによって $\mathrm{M}_{n} \mathrm{~S}$ 介在物の数量を增したもの であり, $\mathrm{M}_{n} \mathrm{~S}$ の数量の範围は, われわれの場合, 英 国鉄鋼協会介在物小委員会の研究上りもはるかに広範 囲である。

\section{2. 供試材料および試験片の準備}

供試材料は本研究のために特に三菱鋼材 (株)内山道 良氏(当時研究部長)によって調製されたものである. すなわち, Table 1゙に示すように他の条件はできるだ け同一に保って $\mathrm{M}_{n}$ と $\mathrm{S}$ の含有量のみを変えた 3 種の

\footnotetext{
* 固溶 $\mathrm{Mn}$ の量の推定值は, Sのすべてが一応 $\mathrm{Mn} \mathrm{S}$ となっている という仮定の下に求めたすのである。実際はこの推定値よりは小ざ いことは当然であるが, 3 種の材料の 固溶 $\mathrm{Mn}$ 量の比較のお捄上 その尺度とはなるであうう
} 
炭素鋼(S15C)が調製された。なお，溶解，造塊，压 延等試験片採取に至るまでの処理操作については別の

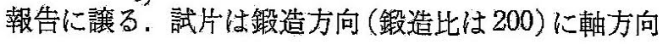
がー致するように採取された。試片加工前に $900^{\circ} \mathrm{C} に$ て30 分焼準された。各材の介在物分布状沉は Photo. 1に示すとおりである。内山氏による介在物測定結果 （JISGO 555 ならびに ASTM B法による判定結果） 家 Table 2 に示す． $\mathrm{E}$ 材は芥在物微量，D材は中間 程度，J材仕きわめて多量のものであることがわかる。 各材のフェライト結晶粒度測定結果も Table 2 に示 した.

\section{3. 実験結果と考察}

疲労試験には小野式回転曲げ試験機を用いた，繰返 速度は毎分 1400 である．各材について得られた $S-N$ 曲線荧 Fig. 1 に示した．実験データの一部を Table 3 执よびムに示した。

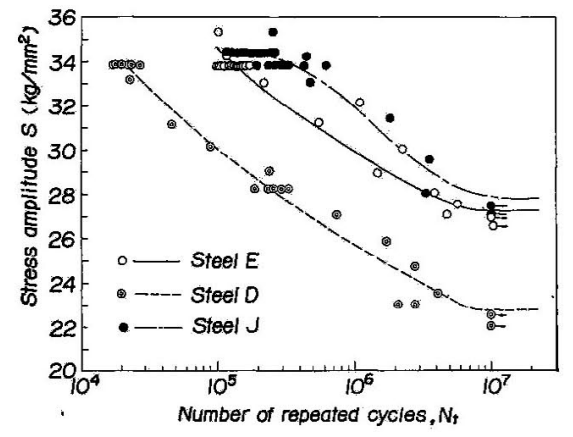

Fig. $1 S-N$ diagram of each steel

\section{(I) 疲労強度}

Fig. 1 に示すように疲労強度はD材， E材，J材の 順に高々なっている. 介在物 rating の順とは一致し ていない，この理由については次のような原因が考え られよう。一つは，D材，E材，J材の順にフェライ ト結晶粒の大ささが小さくなっていることである。 (Table 2) フェライト結晶粒の小さくなるほど疲労強 度が高〈なることは実験的にもたしかめられており， 理論的にも示されている、しかし，介在物のもっとも 多い丁材がもっとも疲労強度が高いということは、こ の程度の結晶粒の大きさのちがいだけによるものとは 考えにくいと思う。すなわち，J材の場合には，D材， $\mathrm{E}$ 材よりも，固溶 $\mathrm{M}_{n}$ の推定量が大である (Table 1 参照）ことも疲労強度增大にきいているものと孝えら れよう，その理由は次のとおりである，固溶 $\mathrm{M}_{n}$ の量 の疲労限におよぼす影響についての研究がまだ知見さ れないのであるが，鋼材の降伏点におよぼす影響につ いての研究によれば，固溶 $\mathrm{M}_{n}$ 量が約 $0.5 \%$ 程度以上 になると，その堌加とともに転位の摩擦力 $\sigma_{i}$ が增加 して降伏点が上昇することが実験的にたしかめられて いる，一方，疲学破買の理論によれば $\sigma_{i}$ の增加は同 時に疲労限の增加となって現われるからである。した がって，次のように説明されるであろう。

（1）E材とD材と起比へると，D材の力が介在物 量も多く，しかも結晶粒が大きいのでE材よりも疲労 強度が低い（ $\mathrm{E}$ 材と $\mathrm{D}$ 材の固溶 $\mathrm{M}_{n}$ 量の相違もある がこのきき方よりむ介在物および結晶粒大さの重甾

Table 1 Chemical composition of steels tested (\%)

\begin{tabular}{c|c|c|c|c|c}
\hline Composition & $\mathrm{C}$ & $\mathrm{Si}$ & $\mathrm{Mn}$ & $\mathrm{P}$ & $\mathrm{S}$ \\
\hline Steel & 0.16 & $0.3 \mathrm{i}$ & 0.56 (Solid solution Mn 0.54) & 0.013 & 0.010 \\
$\mathrm{D}$ & 0.13 & 0.17 & 0.88 (Solid solution Mn 0.57) & 0.013 & 0.183 \\
$\mathrm{~J}$ & 0.15 & 0.23 & 1.17 (Solid solution Mn 0.59) & 0.022 & 0.340 \\
\hline
\end{tabular}

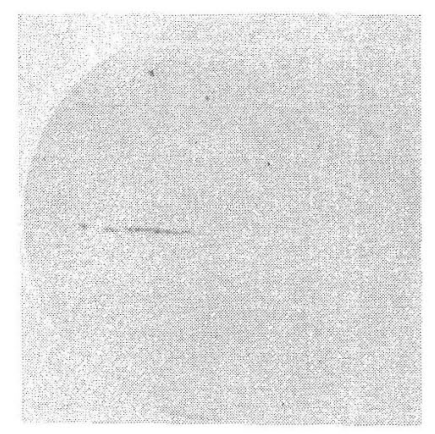

(a) E-steel $(\times 400 \times 1 / 2)$

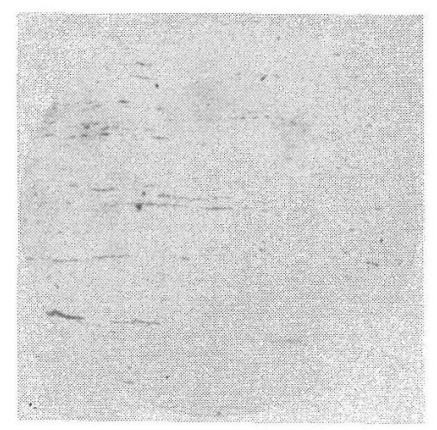

(b) D-steel $(\times 400 \times 1 / 2)$

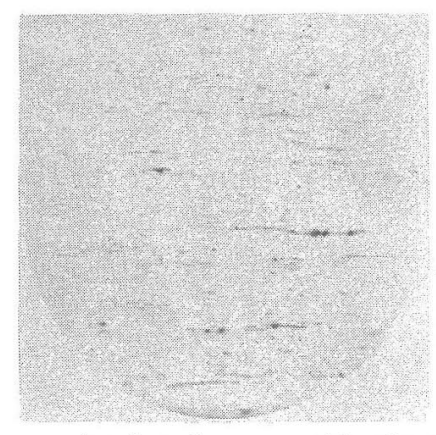

(c) J-steel
$(400 \times 1 / 2) \cdot$

Photo. 1 Typical photographs of non-metallic inclusions in longitudinal section of each steel 
Table 3 Fatigue life of each steel at stress amplitude of $\pm 33 \cdot 8 \mathrm{~kg} / \mathrm{mm}^{2}$

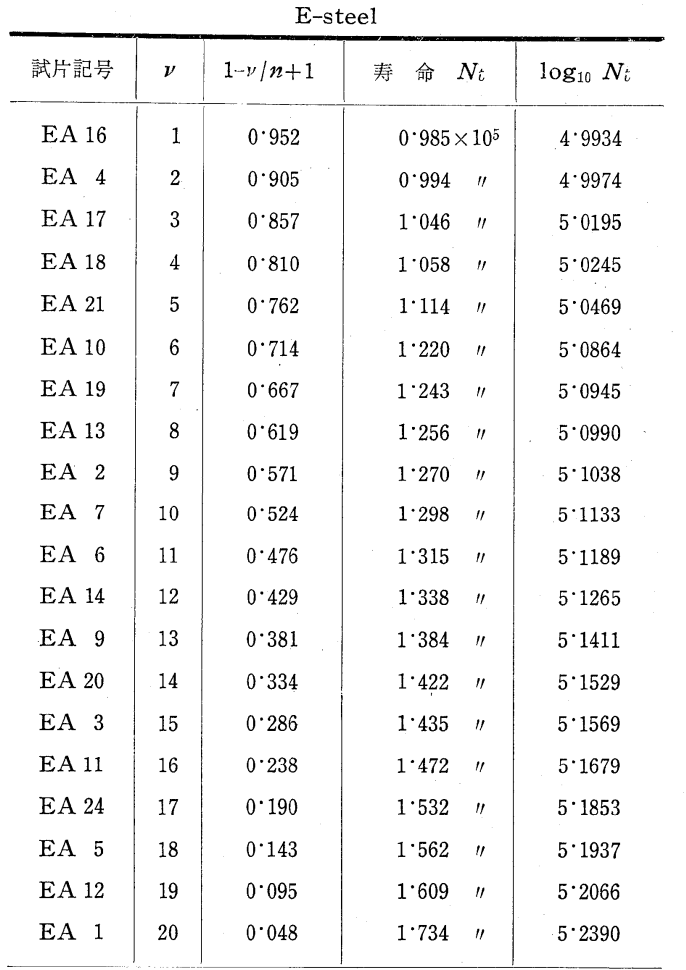

\begin{tabular}{|c|c|c|c|c|}
\hline \multicolumn{5}{|c|}{$\mathrm{J}$-steel } \\
\hline 試片記号 & $\nu$ & $1-\nu / n+1$ & 寿 命 $N$ & $\log _{10} N_{t}$ \\
\hline $\mathrm{J} 40$ & 1 & $0 \cdot 909$ & $1 \cdot 439 \times 1$ & $5 \cdot 1581$ \\
\hline $\mathrm{J} 39$ & 2 & 0.818 & $1 \cdot 954$ & $5 \cdot 2909$ \\
\hline $\mathrm{J} 38$ & 3 & 0.727 & $2 \cdot 392$ & $5 \cdot 3788$ \\
\hline $\mathrm{J} 19$ & 4 & 0.636 & $2 \cdot 517$ & $5 \cdot 4009$ \\
\hline $\mathrm{J} 37$ & 5 & $0 \cdot 545$ & $2 \cdot 539$ & $5 \cdot 4047$ \\
\hline $\mathrm{J} 32$ & 6 & 0.455 & $3 \cdot 087$ & $5 \cdot 4895$ \\
\hline $\mathrm{J} 34$ & 7 & 0.364 & $3 \cdot 297$ & $5 \cdot 5181$ \\
\hline $\mathrm{J} 36$ & 8 & 0.273 & $3 \cdot 332$ & $5 \cdot 5227$ \\
\hline $\mathrm{J} 23$ & 9 & $0 \cdot 182$ & $4 \cdot 349$ & $5 \cdot 6384$ \\
\hline $\mathrm{J} 35$ & 10 & 0.091 & $6 \cdot 225$ & $5 \cdot 7941$ \\
\hline
\end{tabular}

\section{D-steal}

\begin{tabular}{c|c|c|cc|c}
\hline 試片記号 & $\nu$ & $1-\nu / n+1$ & 寿 命 $N_{\hat{t}}$ & $\log _{10} N_{\hat{t}}$ \\
\hline D 24 & 1 & 0.875 & $1.75 \times 10^{4}$ & 4.2430 \\
D 21 & 2 & 0.750 & 1.78 & $\prime \prime$ & 4.2504 \\
D 26 & 3 & 0.625 & 1.99 & $\prime \prime$ & 4.2989 \\
D 25 & 4 & 0.500 & 2.24 & $\prime \prime$ & $4: 3502$ \\
D 20 & 5 & 0.375 & 2.24 & $\prime \prime$ & 4.3502 \\
D 23 & 6 & 0.250 & 2.33 & $\prime \prime$ & 4.3674 \\
D 22 & 7 & 0.125 & 2.71 & $\prime \prime$ & 4.4330 \\
\hline
\end{tabular}

効果の方が大さいためと考えられよう).

（2）また，J材は介在物の量はもっとも多いけれ ぞも, 結晶粒がもっとも小さく，しかも，固溶 $\mathrm{M}_{n}$ の 量が $\mathrm{E}$ 材, $\mathrm{D}$ 材のいずれよりも多くて, 転位の摩擦力 を増大させるということの双方の原因によって，疲労 強度がもっとも高くなっているものとして説明される。

\section{(II) 疲労の統計的性質}

(i) 同一応力振幅での寿命のばらつき Table 2 から $\mathrm{S}=33 \cdot 8 \mathrm{~kg} / \mathrm{mm}^{2}$ でのE材, D材および J 材の寿 命のばらつき（標準偏差 $\sigma_{N}$ ) を計算した結果を Table 2 に示した。すすおち, 次の関係がある（有意水準 1

Table 4 Fatigue life of each steel at equivalent stress amplitude

\begin{tabular}{|c|c|c|c|c|c|}
\hline \multicolumn{6}{|c|}{ J-steel (at $\left.S=34.4 \mathrm{~kg} / \mathrm{mm}^{2}\right)$} \\
\hline 試片記号 & $\nu$ & $1-\nu / n+1$ & 寿 命 $I$ & $N_{i}$ & $\log _{10} N \mathrm{t}$ \\
\hline J 11 & 1 & 0.952 & \multicolumn{2}{|c|}{$1 \cdot 120 \times 10^{5}$} & $5 \cdot 0492$ \\
\hline J 1 & 2 & 0.905 & $1 \cdot 149$ & "I & $5 \cdot 0603$ \\
\hline $\mathrm{J} 16$ & 3 & 0.857 & $1 \cdot 268$ & $" \prime$ & $5 \cdot 1031$ \\
\hline $\mathrm{J} 18$ & 4 & 0.810 & $1 \cdot 298$ & $" \prime$ & $5 \cdot 1133$ \\
\hline J 6 & 5 & $0 \cdot 762$ & $1 \cdot 353$ & $" \prime$ & $5 \cdot 1313$ \\
\hline J 13 & 6 & $0 \cdot 714$ & $1 \cdot 377$ & "I & $5 \cdot 1389$ \\
\hline J 12 & 7 & 0.667 & $1 \cdot 441$ & $" \prime$ & $5 \cdot 1587$ \\
\hline J 10 & 8 & 0.619 & $1 \cdot 443$ & " & $5 \cdot 1593$ \\
\hline J 3 & 9 & 0.571 & $1 \cdot 450$ & $\prime \prime$ & $5 \cdot 1614$ \\
\hline J 7 & 10 & 0.524 & $1 \cdot 469$ & $\prime \prime$ & $5 \cdot 1670$ \\
\hline $\mathrm{J} 17$ & 11 & 0.476 & $1 \cdot 542$ & $\prime \prime$ & $5 \cdot 1881$ \\
\hline $\mathrm{J} 5$ & 12 & 0.429 & $1 \cdot 572$ & $\prime \prime$ & $5 \cdot 1964$ \\
\hline $\mathrm{J} 15$ & 13 & $0 \cdot 381$ & $1 \cdot 734$ & $\prime \prime$ & $5 \cdot 2390$ \\
\hline J 8 & 14 & 0.334 & $1 \cdot 779$ & " & $5 \cdot 2502$ \\
\hline J 9 & 15 & 0.286 & $1 \cdot 973$ & "I & $5 \cdot 2951$ \\
\hline $\mathrm{J} 14$ & 16 & 0.238 & $2 \cdot 041$ & " & $5 \cdot 3098$ \\
\hline J 4 & 17 & $0 \cdot 190$ & $2 \cdot 157$ & $\prime \prime$ & $5 \cdot 3339$ \\
\hline $\mathrm{J} 2$ & 18 & 0.143 & $2 \cdot 449$ & " & $5 \cdot 3890$ \\
\hline $\mathrm{J} 20$ & 19 & 0.095 & $2 \cdot 569$ & $" \prime$ & $5 \cdot 4098$ \\
\hline $\mathrm{J} 21$ & 20 & 0.048 & $2 \cdot 597$ & $" \prime$ & $5 \cdot 4145$ \\
\hline \multicolumn{6}{|c|}{ D-steel (at $\mathrm{S}=28 \cdot 2 \mathrm{~kg} / \mathrm{mm}^{2}$ ) } \\
\hline 試片記号 & $\nu$ & $1-\nu / n+1$ & 寿 命 $I$ & $N_{i}$ & $\log _{i 0} N_{i}$ \\
\hline D 14 & 1 & 0.900 & $1.893 \times$ & $\times 10^{5}$ & $5 \cdot 2772$ \\
\hline D 16 & 2 & 0.800 & $2 \cdot 321$ & $\prime \prime$ & $5 \cdot 3657$ \\
\hline D 15 & 3 & $0 \cdot 700$ & $2 \cdot 361$ & $\prime \prime$ & $5 \cdot 3731$ \\
\hline D 17 & 4 & $0 \cdot 600$ & $2: 573$ & $" \prime$ & $5 \cdot 4104$ \\
\hline $\mathrm{D} 13$ & 5 & $0 \cdot 500$ & $2 \cdot 784$ & $" \prime$ & $5 \cdot 4447$ \\
\hline $\mathrm{D} 10$ & 6 & $0 \cdot 400$ & $2 \cdot 792$ & $\prime \prime$ & $5 \cdot 4459$ \\
\hline D 7 & 7 & $0 \cdot 300$ & $2 \cdot 813$ & $\prime \prime$ & $5 \cdot 4492$ \\
\hline $\mathrm{D} 12$ & 8 & 0.200 & $2 \cdot 860$ & $\prime \prime$ & $5 \cdot 4564$ \\
\hline D 18 & 9 & $0 \cdot 100$ & $3 \cdot 276$ & $" \prime$ & $5 \cdot 5153$ \\
\hline
\end{tabular}

For E-steel (at $\left.\mathrm{S}=33.8 \mathrm{~kg} / \mathrm{mm}^{2}\right)$, see Table 3 
\%)ことがわかる。

$$
\sigma_{N J 33 \cdot 8}>\sigma_{N E 33 \cdot 8}>\sigma_{N D 33 \cdot 8}
$$

ただし， $\sigma_{N J 33 \cdot 8}, \sigma_{N E 33 \cdot 8}$ および $\sigma_{N D 33.8}$ はそれぞ れ J 材, E材およびD材の $\mathrm{S}=33 \cdot 8 \mathrm{~kg} / \mathrm{mm}^{2}$ における 寿命の標準偏差老現わすものとする。一方，介在物 ratingの方は,

$$
I_{R J}>I_{R D}>I_{R E}
$$

の順になっている。ただし， $I_{R J}, I_{R D}$ および $I_{R E}$ は それぞれ J 材，D材および $\mathrm{E}$ 材の介在物 rating を現 わすものとする。（1）式，(2)式を見るとと $\sigma_{N}$ と $I_{R}$ の間には一定の関連性が認められない.

一方，フェライト結晶大きさの方は Table 4 から

$$
G_{N J}>G_{N E}>G_{N D}
$$

である。ただし， $G_{N J}, G_{N E}$ および $G_{N D}$ はそれぞ れ $\mathrm{J}$ 材， $\mathrm{E}$ 材および $\mathrm{D}$ 材のフェライト結晶粒度番号を 現わすものとする。すなわち，（1)式と（3)式とを比 べてみると, 結晶粒の細かいほど疲労寿命のばらつき が大きくなっていることがわかる、これは前報の結果 と全く同様である。また，破壊の確率が結晶粒の小さ いほど小さくなること(Fig. 2)もこれまでの結果と同 様である。なお， E材，D材ならびに J 材とも結晶粒 は小さいのであり，このように結晶粒の小さいもので は疲労寿命の頻度分布曲線が正にひずむ゙（繰返数の

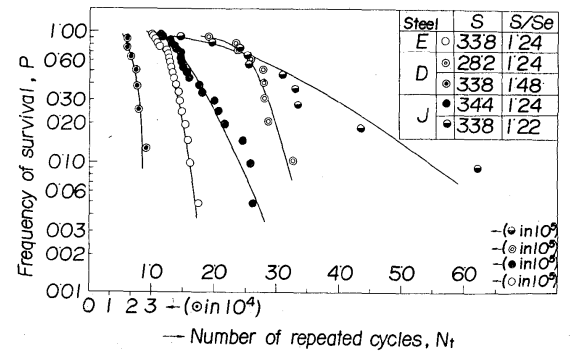

Fig. 2 Survivorship functions
大きい方にひずんでいる)こと (Fig. 2) もこれまでの 研究結果と一致する。

(ii ）等価応力（耐久限度に対する応力比の等しい 応力)振幅での統計的性質 次に，等洒応力比(応力振 幅/耐久限)として，これまでの研究のシリーズとほぼ 等しい比の值として，ここでも 1.24 となるような応 力振幅のところでの統計的㤬質を調べてみる.

\section{a ) 寿命の対数のばらつき (標準偏差) $(\sigma \log N)$ と} 介在物 rating

$\sigma_{\log N, H^{\prime}}$ と $\sigma_{\log N, D}$ とは50\%有意水準にて， $\sigma_{\log N, J}$ と $\sigma_{\log N, D}$ とは $10 \%$ 有意水準にて有意差はない.

$\sigma_{\log N, T}$ と $\sigma_{\log N, E}$ とは2\%有意水準にて有意差がない 程度である。

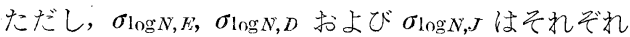
$\mathrm{E}$ 材， $\mathrm{D}$ 材および $\mathrm{J}$ 材の寿命の対数の標準偏差を現わ すものとする。すなわち， $\log$ と介在物 rating との 間には一定の関連性が認められない。この結果は,介 在物の多いほど $\sigma_{\log N}$ が大きいという Epremian たち

* 同一応力振幅 $33.8 \mathrm{~kg} / \mathrm{mm}^{2}$ の疲労寿命の頻度分布曲線化対乙て 正規分布からのひずみを比較するために相加平均の丞わりの 3 次の モーメント $\mu_{3}$ を計算すると, $\mathrm{D}$ 材, $\mathrm{E}$ 材ならびに $\mathrm{J}$ 材に対してそ

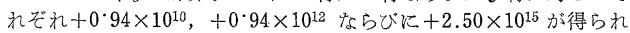
る。したがって結晶粒が小さいもの湮ど正にひずてでいることがわ かる.ここで, Fig. 2 の横䛱炕は繰返数をとって拉り, 各材とも 同種の単位であるから普通の意味のひずみ度は採らなかった。

**等価応力に括ける場合, 試験片数が相違した。このため有意差 検定に過誤を生じないかどうかを調べるたぬ飞E材㧍よび J材から それぞれ 9 本ずつを無作為抽出した場合の検定る行なってるた。 そ の結果は次のと怙りである。

(a) 寿命の対数のばらつき

$\sigma \log N, E$ そ $\sigma \log N, D$ とは $50 \%$ 有意水準飞て有意差なく, $\sigma \log$ $N, J$ と $\sigma \log N, D$ とは20\%有意水準にて有意差がない。 $\sigma \log N, J$ と $\sigma \operatorname{lgg} N, E$ とは $20 \%$ 有意水準にて有意差がない。

(b) 寿命のばらつき

$\sigma_{N, l}$ と $\sigma_{N, D}$ とは $50 \%$ 有意水準にて有意差がなく， $\sigma_{N, E}$ と $\sigma_{N, D}$ とは $5 \%$ 有意水準にて有意差がない, $\sigma_{N, E}$ と $\sigma_{N}, J$ とは $5 \%$ 有意水準にて有意差がない。

したがって，この場合にも介在物 rating と $\sigma \log N$ または $\sigma_{N}$

\begin{tabular}{|c|c|c|c|c|c|c|c|c|c|c|c|c|}
\hline \multirow{2}{*}{ 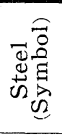 } & \multirow{2}{*}{ 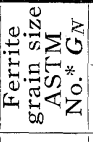 } & \multicolumn{2}{|c|}{ Inclusion ratings } & \multirow{2}{*}{ 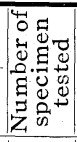 } & \multirow{2}{*}{ 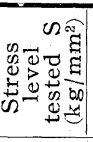 } & \multirow{2}{*}{ 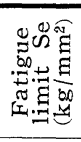 } & \multirow{2}{*}{ 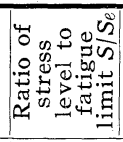 } & \multirow{2}{*}{ 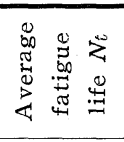 } & \multirow{2}{*}{ 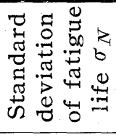 } & \multirow{2}{*}{\multicolumn{2}{|c|}{ 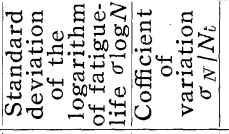 }} & \multirow{2}{*}{$\begin{array}{l}\frac{1}{*} \\
\vdots \\
\vdots \\
\vdots \\
\vdots \\
\vdots\end{array}$} \\
\hline & & JIS GO $555^{*} I_{R}$ & $\mathrm{SAE}$ & & & & & & & & & \\
\hline $\mathrm{E}$ & $8 \cdot 5$ & $\begin{array}{l}\mathrm{dA} 60 \times 400=0.07 \\
\mathrm{~dB} 60 \times 400=0.05 \\
\mathrm{dC} 60 \times 400=0.05\end{array}$ & $\begin{array}{c}\mathrm{dt} \\
2 \cdot 3-1^{55} \\
-\mathrm{A}\end{array}$ & 20 & $33 \cdot 8$ & $27 \cdot 3$ & $1 \cdot 24$ & $1.314 \times 10^{5}$ & $2 \cdot 04 \times 10^{4}$ & 0.0685 & $15 \cdot 5$ & $0 \cdot 750$ \\
\hline \multirow{2}{*}{ D } & \multirow{2}{*}{$8 \cdot 0$} & \multirow{2}{*}{$\begin{array}{l}\mathrm{dA} 60 \times 400=0.63 \\
\mathrm{~dB} 60 \times 400=0.09 \\
\mathrm{dC} 60 \times 400=0.07\end{array}$} & \multirow{2}{*}{$\begin{array}{l}\text { dgt } 1404 \\
5 \cdot 7-1-D\end{array}$} & 7 & $33 \cdot 8$ & \multirow{2}{*}{$22 \cdot 8$} & $1 \cdot 48$ & $0.215 \times 10^{5}$ & $0.313 \times 10^{4}$ & 0.0629 & $14 \cdot 6$ & 0.814 \\
\hline & & & & 9 & $28 \cdot 2$ & & $1 \cdot 24$ & $2.630 \times 10^{5}$ & $3.76 \times 10^{4}$ & 0.0649 & $14 \cdot 3$ & $0 \cdot 720$ \\
\hline \multirow{2}{*}{$J$} & \multirow{2}{*}{$9 \cdot 0$} & dA $60 \times 400=1 \cdot 10$ & dgt 9084 & 10 & $33 \cdot 8$ & \multirow{2}{*}{$27 \cdot 8$} & $1 \cdot 22$ & $3 \cdot 113 \times 10^{5}$ & $12.9 \times 10^{4}$ & $0 \cdot 169$ & $41 \cdot 4$ & $0 \cdot 462$ \\
\hline & & $\mathrm{dC} 60 \times 400=0.08$ & $6-1-\mathrm{D}$ & 20 & $34 \cdot 4$ & & $1 \cdot 24$ & $1.689 \times 10^{5}$ & $4.49 \times 10^{4}$ & $0 \cdot 110$ & $26 \cdot 6$ & 0.663 \\
\hline
\end{tabular}

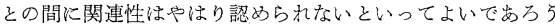

Table 2 Summary of test data

* For each steel, suffixes such as $G_{N E}$ and $I_{R D}$ are used corresponding to steel $\mathrm{E}$ and steel D respectively.

** $\mathrm{c}=$ Incubation cycles 
の結論に対して否定的であることも前報同様で注目す ベきことである。

\section{b） 寿命のばらつき（標準偏差） $\left(\sigma_{N}\right)$ と介在物 rating}

$\sigma_{N}, J$ と $\sigma_{N},{ }_{D}$ とは $50 \%$ 有意水準にて, $\sigma_{N},{ }_{E}$ と $\sigma_{N}, D$ は $1 \%$ 有意水準にてそれぞれ有意差なく， $\sigma_{N}, E$ と $\sigma_{N}, y$ とは $1 \%$ 有意水準にて有意差がある。 (ii) の (b)の結果は等価応力振幅にて一般にばらつき はほぼ等しいという前報の結論と同様である.

\section{4. 結論}

（1）低炭素鋼の縦方向材の回転曲げ疲労の統計的 性質と本実験範囲程度の介在物 rating との間には従 来の結論に反して一定の関係が認められない.

（2）鋼の疲労破壊の統計的悎質にはフェライト結 晶粒の大きさが影響をもつと考えられる。

(3) 同一応力振幅にては結晶粒が小さくなるほど,

（i）疲労寿命のばらつきは大きくなり，

(ii）疲労寿命の頻度分布曲線は正にひずんでくる （Nの大きい方にひずんでくる）

（iii）破壊の確率は減ってくる.

(4) 等価応力振幅に対しては疲労寿命のばらつき は介在物 rating やフェライト結晶粒大ささに関せず
ほぼ等しいようである。

（5）低炭素鋼の縦方向材の疲労強度は介在物とし ての $\mathrm{M}_{n} \mathrm{~S}$ の量がかなり多くなってもそれほど影響 を受けない、フェライト結晶粒の大きさなど本体 (matrix) の組織 (structure) の影響もかなり大きい.

なお，本研究は綜合研究「金属材料の各種介在物と 疲労に関する研究」の一部として行なわれたものであ り, 試作材の調製, 試料準備および介在物判定を担当 いただいた三菱鋼材(株)内山道良部長に謝意を表する 次第である。

\section{参 考 文 献}

1）たと党ば, T. Yokobori, Proc. 2 nd Jap. Cong. Test. Mat., p. 10 (1959)

2) P.H. Frith, J. Iron and Steel Inst., 180 p. 26 (1955)

3）綜合研究「金属材料の各種介在物々疲労.! (未発表)

4) H. Hendus and G. Kraus, Z. Met'kde, Vol. 46, 716 (1955)

5) 横堀, 前川, 日本機械学会第 38 期通常総会講演前刷 (1961)

6）横堀, 日本機械学会誌, 65, 523, 1076 (1962), 65, 524, 1206 (1962)

7) J. Heslop and N.J. Petch, Phil. Mag., 12, 649 (1957)

8）たと总ば，横堀，材料試験， 6, 45，378 (1957)，7，58，371 (1958)

9) E. Epremian and R.F. Mehl, ASTM STP, No. 137 p. 25 (1953)

10）横堀，森田，高橋（未発表）

\section{外国交献紹介

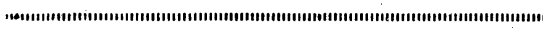 \\ 金属材料}

\section{イタリーにおける実物疲労試験の歴史的背景}

Historical Background of Full-Scale Fatigue Testing in Italy, V. Villa, "Full-Scale Fatigue Testing of Aircraft Structures," Edited by F.J. Plantewa and J. Schijve Pergamon Press (1961)

1940 年以来, 第 2 次世界大戦中心よびその直後数年 間にイタリーで行なわれた実物航空機構造の疲労試験 の傾向を紹介したものである.

この試験の主たる目的は, 構造の中疲労に弱い部分 の検出と，耐空性保証のための耐久性の立証である.

試験方法としては繰返変位を与えるか，共振を利用 するか，非共振状態で荷重を繰り返すかのどれかを採 用することになる。

同一の構造について共振試験結果と繰返荷重試験結 果とはよく一致している。 もし付加質量の分布がうま くいき，動的变位およびひずみに対し正確な測定がで きるなら, 共振法の利用価值はきわめて大であろう.

ある場合には結果は実際の荷重分布に必ずしも一致
しないことがあり, 一方, 疲労を受けやすい部分の検 出という点ではクラックの発生する場所も破損を生ず る場所もいずれも，またクラックの進展速度も，外力 のレベルに依存することが多かった。（関 護雄）

\section{ダメジを受けた構造物の引張強さ一関連試験データ} を用いての解析法 The Ultimate Strength of Damaged Structure-Analysis Methods with Correrating Test Data, W.J. Crichtow "Full-Scale Fatigue Testing of Aircraft Structures," Edited by F.J. Plantema and J. Schijve Pergamon Press(1961)

この論文は直接疲労試験には関係ないが，よくいわ れるfail-safe などに関連して，ダメジを受けたー実験 的には始めからクラックの存在する構造物がどれだけ の静的強度を持っているかということを調べたもので ある.クラックの進展を止めるために, 補強材を入れ たり，重ね継手にしたりすることの影響が広く論ぜら れている。

(関 護雄)

(445頁へ) 